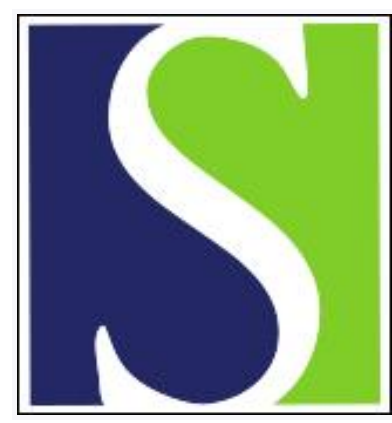

Scand J Work Environ Health 1998;24(3):165-174

https://doi.org/10.5271/sjweh.295

Issue date: Jun 1998

Occurrence, trends and environmental etiology of pancreatic cancer

by Weiderpass E, Partanen T, Kaaks R, Vainio H, Porta M, Kauppinen T, Ojajärvi A, Boffetta P, Malats N

Key terms: environmental exposure; epidemiology; occupational exposure; pancreatic neoplasms; review; risk factor

This article in PubMed: www.ncbi.nlm.nih.gov/pubmed/9710368

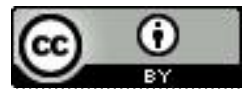




\title{
Occurrence, trends and environmental etiology of pancreatic cancer
}

\author{
by Elisabete Weiderpass, MD, ${ }^{1}$ Timo Partanen, PhD, ${ }^{2,3}$ Rudolf Kaaks, PhD, ${ }^{3}$ Harri Vainio, MD, ${ }^{3}$ Miquel \\ Porta, MD, ${ }^{4}$ Timo Kauppinen, PhD, ${ }^{2}$ Anneli Ojajärvi, MSc, ${ }^{2}$ Paolo Boffetta, MD, ${ }^{3}$ Núria Malats, MD ${ }^{3,4}$
}

\begin{abstract}
Weiderpass E, Partanen T, Kaaks R, Vainio H, Porta M, Kauppinen T, Ojajärvi A, Boffetta P, Malats N. Occurrence, trends and environmental etiology of pancreatic cancer. Scand J Work Environ Health 1998;24(3):165-174.

This review summarizes data on the occurrence, the trends, and the life-style, environmental, occupational and genetic determinants of pancreatic cancer. Epidemiologic evidence implicates tobacco smoking as one cause. The evidence regarding alcohol consumption is inconsistent. Although both positive and inconclusive findings are encountered, the bulk of the evidence on coffee consumption is negative. Fat intake is linked with obesity and diabetes mellitus, which are risk factors for pancreatic cancer. Fruit and vegetable consumption appears to be protective. No occupational or environmental agent has been confirmed to increase the risk, but epidemiologic evidence is inconsistent. Little is known about the role of genetic polymorphisms of metabolic enzymes in pancreas carcinogenesis. Pancreatic cancer shows high rates of mutations of Ki-ras and losses or mutations of tumor suppressor genes (p53, p16 ${ }^{\text {INK4A }}$, and SMAD4/DPC-4). Ki-ras mutations have been associated with life-style factors in relation to pancreatic cancer, but the evidence is still scant and inconsistent.
\end{abstract}

Key terms environmental exposure, epidemiology, occupational exposure, pancreatic neoplasms, rewiew, risk factors.

A total of 181000 new cases of pancreatic cancer (International Classification of Diseases: code 157 in 9 th revision and code $\mathrm{C} 25$ in 10 th revision) are annually diagnosed worldwide (1). Owing to its high fatality, pancreatic cancer is the 5th leading cause of cancer deaths in industrialized nations. Most pancreatic cancers derive from the exocrine component. Endocrine tumors arising in islet cells constitute about $5 \%$ of all pancreatic cancers (2).

The causes of pancreatic cancer are obscure for the most part. This review summarizes data on the occurrence, the trends, and the life-style, environmental, occupational and genetic determinants of exocrine pancreatic cancer.

\section{Descriptive epidemiology}

Because of the rapid fatality from pancreatic cancer, its incidence and mortality rates follow each other closely and increase steeply among people $40-70$ years of age. The populations of industrialized nations appear to carry a higher burden of pancreatic cancer than those of less industrialized nations. Regionally, the highest annual age-adjusted incidence rates in 1990 were estimated for blacks in central Louisiana (20.8/100 000) and San Francisco (13.1/100 000). The lowest rates were reported for west and middle Africa, temperate South America, southeastern and southern Asia, and Melanesia (3). No consistent urban-rural gradient is discernible (4).

\section{Time trends}

Incidence rates have been rising in developed countries since the 1960s but have leveled or are leveling off in populations such as those of the Nordic countries, Scotland, Northern Ireland (5-7) and Connecticut (in the United States) (8). The increase may be attributable to the increased sensitivity of modern preoperative diagnostic methods, to the greater accessibility of the health

1 Department of Medical Epidemiology, Karolinska Institute, Stockholm, Sweden.

2 Finnish Institute of Occupational Health, Helsinki, Finland.

3 International Agency for Research on Cancer, Lyon, France.

4 Municipal Institute for Medical Research, Barcelona, Spain.

Reprint requests to: Dr Elisabete Weiderpass, Department of Medical Epidemiology, Karolinska Institute, S-17177 Stockholm, Sweden. [e-mail: Elisabete.Weiderpass@MEP.KI.SE] 
system to people, and to better registration procedures, but an actual increase in incidence also appears to have taken place (7)

\section{Gender ratio}

The average age-adjusted male-to-female ratio of pancreatic cancer incidence has been reported to be 1.6 for developed nations and 1.1 for developing nations (9). The age-adjusted incidence ratio between developed and developing countries was 2.2 for men and 1.6 for women during the same time period (9). If it is assumed that these figures largely reflect etiologies, not just diagnostic practices, some major etiologic factor(s) may have been more prevalent for men than for women in developed countries, and more prevalent for both men and women in developed countries than in developing countries. Leading candidates for the sources of such differentials would be tobacco smoke and chemical exposures.

\section{Migrant studies}

Migrant studies suggest that environmental factors influence the risk of pancreatic cancer. Studies have been conducted on Italian migrants, on migrants from Europe to Australia and Israel, and from Mexico to Los Angeles. Pancreatic cancer rates have usually shifted from the level of the country of origin toward that of the host country. However, the patterns are not consistent and depend on the countries and their levels of pancreatic cancer mortality, as well as on factors such as age at arrival and recency of migration $(10,11)$.

\section{Socioeconomic status}

While there seems to be a tendency towards higher ageadjusted pancreatic cancer risk in industrialized countries, pancreatic cancer is not consistently associated with socioeconomic status within national populations, as witnessed by data from 14 countries (12).

\section{Tobacco, alcohol and coffee consumption}

\section{Tobacco smoking}

Tobacco smoking is the single substantiated cause of exocrine pancreatic cancer (13). The estimated proportion of cases attributable to smoking in the United States ranges from $26 \%$ to $52 \%(14-17)$; in northern Italy, it is $20 \%$ for men and $5 \%$ for women (5). Results from at least 27 studies are available. With the exception of the indeterminate results of 3 studies $(9,18,19)$, all studies indicate cigarette smoking as a cause of pancreatic cancer $(5,16,17,20-44)$. High daily doses of tobacco smoke have been associated with risk ratios of the order of 2 3 , occasionally reaching values over 5 . A multicentric case-referent study on pancreatic cancer (45) convincingly demonstrated a consistent excess for ever-smokers and an increasing trend with increasing lifetime consumption, both for men and women, at all study centers.

An absence of a positive dose-response (24, 46-48), a late positive dose-response $(25,31,39)$, and a rapid reduction of pancreatic cancer risk after the discontinuation of smoking $(15,16,31,42)$ have been reported, the results suggesting a late stage component in tobacco smoke carcinogenicity (16). However, not all epidemiologic data are compatible with the late effect notion, and it is conceivable that tobacco smoke may affect both early- and late-stage pancreas carcinogenesis. One large multicentric study (45) reported risk reduction to the never-smoker level 15 years after the cessation of smoking, irrespective of the amount smoked.

The pancreatic carcinogens in tobacco smoke have not been identified. Two tobacco-specific nitrosamines, 4-(methylnitrosamino)-1-(3-pyridyl)-1-butanone (NNK) and N'-nitrosonornicotine (NNN), have been proposed as causative agents of pancreatic cancer in association with the use of tobacco products (49). Little is known of the role of the pancreas in the metabolism of carcinogens involved in exocrine pancreatic cancer. There is a need to assess whether alcohol, coffee, and other exposures modify the metabolism of pancreas carcinogens (50).

\section{Alcoholic beverages}

Alcoholic beverages are carcinogenic to humans (51). While the evidence for cancers of the upper aerodigestive tract is strong and consistent, for pancreatic cancer it is not. Several epidemiologic studies $(20,21,25-27$, $44,47,52-56$ ) have reported a pancreatic cancer excess. Nine cohort studies yielded a consolidated risk ratio (RR) of 1.2 [95\% confidence interval $(95 \%$ CI) $0.9-1.4$ ] for heavy consumers (57). Silverman et al (58) found an increased risk among heavy alcohol drinkers in the United States, particularly among black nonsmokers. Twentytwo studies with a reasonable power to detect a positive association between alcohol consumption and the risk of pancreatic cancer failed to do so $(15,16,18,19,26,30$, $34,35,37,39,40,41,43,46,48,59-65)$. On occasion the excess may have been a result of confounding by tobacco smoking (34). It has been suggested that beer (25, $27,47,63,66)$ or whisky $(56)$, both of which contain higher nitrosamine levels than other alcoholic beverages (67), increase the risk of pancreatic cancer. The only substantiated link between alcohol consumption and pancreatic cancer is through pancreatitis. (See the later discussion.)

\section{Coffee}

Coffee consumption has been associated with a risk of pancreatic cancer in several epidemiologic studies $(15$, 
$16,34,40,46,56,60,68)$, the risk ratios being on the order of 2-3 for those who drink $\geq 5$ cups daily. A doseresponse was shown in some studies. Confounding from smoking may have been possible in some of the studies however. A large number of studies failed to reproduce the association $(18,19,22,23,25,27,30,32,39,41-$ $44,48,55,64,65,69-78)$. It is possible that coffee potentiates or decreases the effect of other risk factors, possibly depending on metabolizing phenotypes (79).

\section{Dietary factors}

\section{Geographic correlation studies}

Ecological studies have associated high pancreatic cancer rates with low per capita availability of beans and vegetables and with the high availability of fats and oils, sugar, eggs, and meat ( $80-83$ ). For milk, positive (80) and negative (83) associations have been reported, while, for fat, positive associations have been reported, mainly for animal fat. Negative associations have been reported for caloric intake from foods of vegetable origin (84). In industrialized western societies, where pancreatic cancer rates are high, diet is characterized by an increased consumption of total and saturated fats, lower intakes of total carbohydrates but higher intakes of highly refined carbohydrates and sugars, and higher intakes of protein and animal fats.

\section{Case-referent studies and prospective cohort studies}

Food groups. Eleven of 12 case-referent studies $(15,27$, $30,41,48,66,85-89$ ) and 2 prospective cohort studies $(18,48)$ reported a decreased pancreatic cancer risk at high consumption levels of vegetables or fruit. For meat and meat products, 6 case-referent studies $(16,27,48$, $41,85,90)$ and 3 cohort studies $(42,44,56)$ reported a positive association with pancreatic cancer. Four casereferent studies $(15,86,88)$ failed to do so, and 1 casereferent study suggested protection with high pork meat intake. The strength of the consolidated evidence for an excess associated with meat consumption is only moderately convincing (table 1 ).

Total energy, macronutrients and dietary fiber. Most of the current evidence on pancreatic cancer and total energy intake and total macronutrient intake comes from a multicentric case-referent study conducted in Adelaide, Australia (30); Toronto (91) and Montreal (84), Canada; Opole, Poland (92); and The Netherlands (88). A pooled analysis, covering 802 cases and 1669 referents revealed an increased risk at high levels of total energy intake and high total carbohydrate intake $(93,94)$ (table 2 ). The carbohydrate finding was largely influenced by the Adelaide data, while the risk for the other areas was generally lower and nonsignificant $(84,94)$. A significant decrease in pancreatic cancer risk at high intakes of dietary fiber was revealed. In centers, there was clear evidence of protection from high fiber intakes. This finding suggests that the pancreatic cancer excess at high carbohydrate intake may be more related to a high intake of refined carbohydrates devoid of fiber components. This possibility was not confirmed by further, more-detailed analyses of the same data, however. In the Adelaide component, there was a strong inverse association between pancreatic cancer risk and high intake of total fat, which one would expect, given the strong increase in risk of pancreatic cancer for high energy-adjusted intake of total carbohydrates. Additional inverse associations between

Table 1. Pancreatic cancer and diet - main results from case-referent studies. $(+=$ significantly increased risk, $-=$ significantly reduced risk, $(-)$ and $(+)=$ borderline significant relative risk (reduction or increase, respectively), $0=$ no significant association)

\begin{tabular}{|c|c|c|c|c|c|c|c|c|c|}
\hline Study & Country & $\begin{array}{l}\text { Vegetables, } \\
\text { fruits }\end{array}$ & $\begin{array}{c}\mathrm{C} \\
\text { Vitamin }\end{array}$ & $\begin{array}{c}\text { Beta- } \\
\text { carotene }\end{array}$ & $\begin{array}{l}\text { Dietary } \\
\text { fiber }\end{array}$ & $\begin{array}{c}\text { Total } \\
\text { fat }\end{array}$ & $\begin{array}{l}\text { Saturated } \\
\text { fats }\end{array}$ & Protein & $\begin{array}{c}\text { Total } \\
\text { carbohydrates }\end{array}$ \\
\hline Durbec et al, 1983 (47) & France & & & & & + & & 0 & 0 \\
\hline Gold et al, 1985 (15) & United States & - & & & & & & & \\
\hline Norell et al, $1986(41)$ & Sweden & - & & & & & & & \\
\hline Mack et al, $1986(16)$ & United States & 0 & & & & & & & \\
\hline Raymond et al, 1987 (66) & Switzerland & - & & & & & & & \\
\hline Falk et al, 1988 (48) & United States & - & - & 0 & & & & & \\
\hline Olsen et al, 1989 (27) & United States & - & & & & & & & \\
\hline Goto et al, 1990 (85) & Japan & - & & & & & & & \\
\hline Farrow \& Davis $1991(90)$ & United States & & & & & 0 & & + & \\
\hline Howe et al, $1990(91)$ & Canada & & - & 0 & - & 0 & 0 & 0 & + \\
\hline Negri et al, 1991 (87) & Italy & - & & & & & & & \\
\hline $\begin{array}{l}\text { Bueno de Mesquita et al, } \\
1991 \text { (88) }\end{array}$ & Netherlands & - & 0 & 0 & - & $(-)$ & - & 0 & 0 \\
\hline Baghurst et al, 1991 (30) & Australia & - & 0 & 0 & - & - & - & 0 & + \\
\hline Ghadirian et al, 1991 (84) & Canada & - & $(-)$ & 0 & - & + & $(+)$ & 0 & 0 \\
\hline Zatonski et al, 1991 (92) & Poland & & $(-)$ & & - & $(-)$ & 0 & 0 & 0 \\
\hline Kalapothaki et al, 1993 (95) & Greece & & $(-)$ & & - & 0 & 0 & 0 & $0 /-$ \\
\hline Lyon et al, $1993(89)$ & United States & $(-)$ & & & & & & & \\
\hline
\end{tabular}


Table 2. Data on pancreatic cancer and diet from a multicentric case-referent study. (OR $=$ odds ratio, $95 \% \mathrm{Cl}=95 \%$ confidence interval). [adapted from From Howe \& Burch, 1996 (94)]

\begin{tabular}{|c|c|c|c|c|c|c|c|c|}
\hline \multirow[t]{3}{*}{ Dietary component } & \multicolumn{7}{|c|}{ Quartiles of population distribution of intake levels } & \multirow[t]{3}{*}{$P$ for trend } \\
\hline & \multirow[t]{2}{*}{1 (low) } & \multicolumn{2}{|r|}{2} & \multicolumn{2}{|r|}{3} & \multicolumn{2}{|c|}{4 (high) } & \\
\hline & & OR & $95 \% \mathrm{Cl}$ & OR & $95 \% \mathrm{Cl}$ & OR & $95 \% \mathrm{Cl}$ & \\
\hline Total fat & 1.0 & 0.81 & $0.60-1.08$ & 1.00 & $0.74-1.35$ & 0.76 & $0.56-1.04$ & 0.23 \\
\hline Saturated fats & 1.0 & 0.81 & $0.60-1.08$ & 1.01 & $0.74-1.38$ & 0.83 & $0.59-1.18$ & 0.58 \\
\hline Garbohydrates & 1.0 & 1.22 & $0.91-1.63$ & 1.42 & $1.06-1.92$ & 1.74 & $1.26-2.40$ & 0.01 \\
\hline Protein & 1.0 & 0.83 & $0.63-1.11$ & 0.97 & $0.73-1.30$ & 0.91 & $0.67-1.24$ & 0.78 \\
\hline Fiber & 1.0 & 0.66 & $0.50-0.87$ & 0.56 & $0.41-0.76$ & 0.42 & $0.30-0.58$ & $<0.01$ \\
\hline
\end{tabular}

Table 3. Industries and occupations with reported excess risks of pancreatic cancer in at least 2 epidemiologic studies.

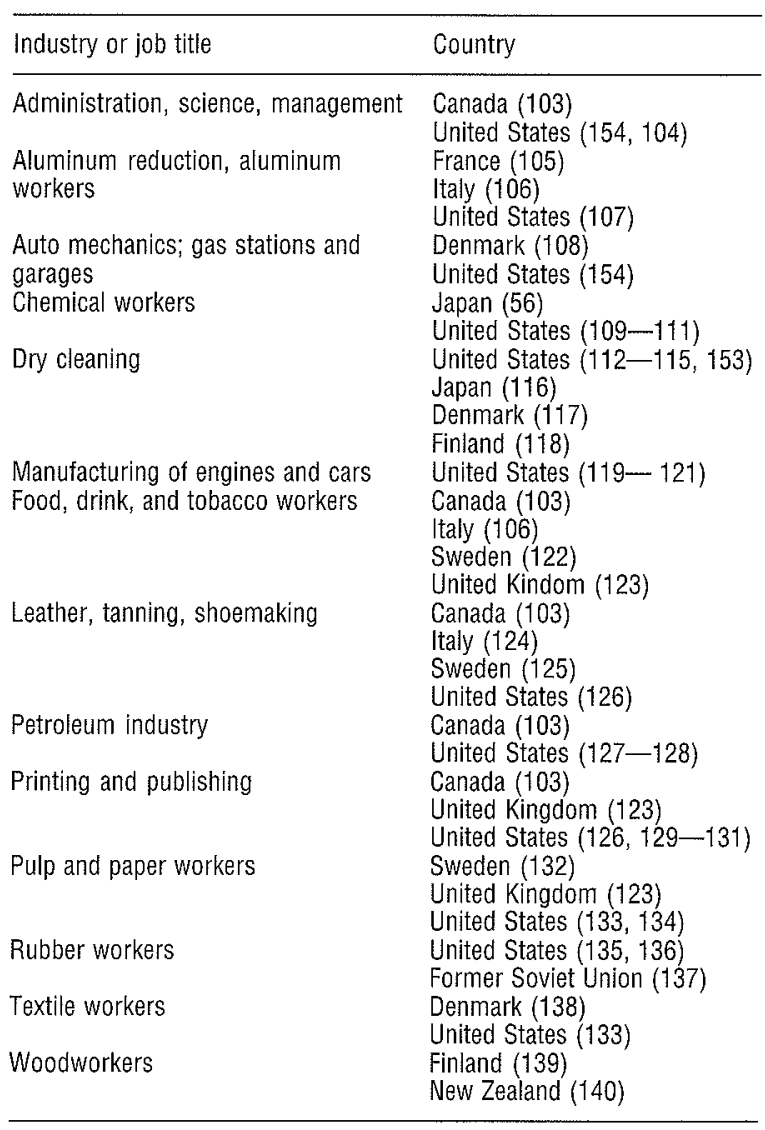

pancreatic cancer and total fat intake were found in the Dutch and Polish studies; for Montreal, however, the association was positive.

The effects of total energy intake and macronutrients have been investigated in 3 additional case-referent studies $(47,90,95)$. A French study (43) found an excess risk for high total fat intake, but the finding was unadjusted for total energy intake. The western Washington, United States (90), and Athens, Greece (95), studies did not find associations for either total or saturated fat or total carbohydrates. For protein, 9 case-referent studies (including the multicentric study) failed to show a clear association with pancreatic cancer risk, while 1 study (90) reported an excess at high intake levels.

Micronutrients. A negative association between pancreatic cancer risk and intake levels of vitamin $C$ has been repeatedly reported $(48,84,91,92,94,95)$. Associations with the intake levels of carotenoids were generally weaker and nonsignificant. One prospective cohort study on serum concentrations of carotenoids reported a significant inverse association with serum levels of lycopene (96).

Obesity. Few studies have addressed obesity and pancreatic cancer. Two $(35,97)$ reported positive associations between obesity and pancreatic cancer risk, which were not confirmed in other studies $(16,36,64,84,91,98)$.

\section{Environmental and occupational exposures}

Occasional excess pancreatic cancer risks have been reported for exposures in the general environment. Chlorinated drinking water was found to be associated with a significant excess (OR 2.2) (99). The evidence from ecologic studies is, however, inconclusive (100). The epidemiologic evidence for a causal association between exposure to ionizing radiation and pancreatic cancer is weak (101). Since active tobacco smoking increases the risk of pancreatic cancer, environmental tobacco smoke may compound the tobacco-related burden of pancreatic cancer; relevant data, however, are lacking (102), except for positive findings from Japan (65).

Workplace exposures may increase the risk of pancreatic cancer. The results of a fair number of epidemiologic studies that have linked industries and job titles with an excess of pancreatic cancer are heterogeneous and inconsistent, and exposures shared by alleged high-risk jobs are hard to identify. The population etiologic fraction due to occupational exposures for pancreatic cancer in Montreal, Canada, has been estimated to be $26 \%$ (103).

No singular occupational exposure has been confirmed to increase the risk of pancreatic cancer with high probability. Most of the associations with single 
chemical agents emerged in 1 study only. The separation between spurious and causal associations presents serious difficulties.

Agents associated with increased risk are shown in table 3. [See also Kauppinen et al (141) for data from references 142-149.] Among them, only aluminum, ionizing radiation, styrene, and unspecified pesticides have been associated with excess risk in more than 1 epidemiologic study.

To complete the preceding listing, studies linking job titles and industries with pancreatic cancer excess were identified. Out of 65 high-risk entries identified in epidemiologic studies, 40 were allocable as inputs into a jobexposure matrix (JEM) that linked 209 job title entries in the United Kingdom with 50 agents (150). For each agent, the proportion of the number of job titles encountered in the pancreatic cancer (PC) excess list out of all 40 pancreatic cancer excess job titles $\left(\mathrm{P}_{\mathrm{PC}}\right)$ was divided by the proportion of the number of job titles encountered in the entire matrix for the same agent $\left(\mathrm{P}_{\mathrm{JEM}}\right)$ out of all 209 job titles in the matrix. The ratio $\mathrm{P}_{\mathrm{PC}} / \mathrm{P}_{\mathrm{JEM}}$ was calculated for each agent. Agents with at least 5 job titles in the pancreatic cancer excess list and a $\mathrm{P}_{\mathrm{PC}} / \mathrm{P}_{\mathrm{JEM}}$ of $>2.0$ were extracted. The following 5 agents were identified: dyes $\left(\mathrm{P}_{\mathrm{PC}} / \mathrm{P}_{\text {JEM }} 2.6\right)$, organic dusts $\left(\mathrm{P}_{\mathrm{PC}} / \mathrm{P}_{\mathrm{JEM}} 2.5\right)$, wood dust $\left(\mathrm{P}_{\mathrm{PC}} / \mathrm{P}_{\mathrm{JEM}} 2.2\right)$, mercury $\left(\mathrm{P}_{\mathrm{PC}} / \mathrm{P}_{\text {JEM }} 2.0\right)$, and benzene $\left(\mathrm{P}_{\mathrm{PC}} / \mathrm{P}_{\mathrm{JEM}} 2.0\right)$. See Anderson et al (151) for additional data.

The preceding approach lacks sensitivity when moderate excesses have been found in several studies. Dry cleaning represents such a case. A host of chemicals has been employed in dry cleaning, including petroleum-derived solvents and, subsequently, chlorinated hydrocarbon solvents, which comprise $90 \%$ of the solvents used in dry cleaning in Europe today (152). Using the latest updates of populations studied after several consecutive follow-up periods, we searched for studies informative of pancreatic cancer risk among dry cleaning workers. We classified the studies according to study design and aggregated the relevant results with a fixed log risk ratio meta-regression model and obtained a consolidated risk ratio (RR) of 1.6 (95\% CI 1.2-2.2) for the 5 "analytical" studies and 0.9 for the rest of the studies (table 4). The latter group did not show significant heterogeneity between studies $(\mathrm{P}=0.56)$, the $\mathrm{RR}$ values ranging from 1.2 to 3.1 . Percholoroethylene seemed to have been the major exposing agent in at least 2 studies $(147,153)$. An additional study (154), not included in the meta-analysis, suggested an exposure-response gradient for pancreatic cancer risk and combined exposure to dry cleaning and gasoline. At $>10$ years of exposure, the odds ratio was a significant 5.1.

\section{Medical conditions}

Allergies, cholecystitis and gallstones, and gastric surgery have been sporadically associated with pancreatic cancer. For 2 additional conditions, pancreatitis and diabetes mellitus, a relatively large number of studies is available.

\section{Pancreatitis}

Pancreatitis, both chronic and acute, is frequently caused by heavy alcohol consumption. The chronic variety has been linked with pancreatic cancer $(5,53,57,62,155$ -

Table 4. Epidemiologic data on pancreas risk in dry cleaning. Data aggregated by fixed metaregression model, where weight was the inverse error of the variance. $(\mathrm{RR}=$ risk ratio, $95 \% \mathrm{Cl}=95 \%$ confidence interval, $\mathrm{PCE}=$ perchloroethylene, $\mathrm{PS}=$ petroleum solvents, TCE $=$ trichloroethylene, TCTF = trichlorotrifluoranthene, SIR = standardized incidence ratio, SMR = standardized mortality ratio)

\begin{tabular}{|c|c|c|c|c|c|}
\hline Reference & Country & Exposure or circumstance & $R R$ & $95 \% \mathrm{Cl}^{\mathrm{a}}$ & Weight \\
\hline \multicolumn{6}{|l|}{ Proportionate studies } \\
\hline Katz \& Jowett, 1981 (112) & United States & Laundry and dry cleaning & 1.1 & $(0.5-2.1)$ & 7.5 \\
\hline Nakamura, $1985(116)$ & Japan & Laundry and dry cleaning (PS, PCE) & & & \\
\hline Men & & & 0.6 & $(0.3-1.2)$ & 8.0 \\
\hline Women & & & 0.4 & $(0.1-1.3)$ & 2.3 \\
\hline Duh \& Asal, 1984 (113) & United States & Dry cleaning & 0.6 & $0.2-1.7$ & 3.4 \\
\hline Petrone, $1988(114)$ & United States & Dry cleaning (PS) & 2.0 & $0.9-3.7$ & 7.7 \\
\hline Aggregate & & & 0.9 & $0.6-1.3$ & \\
\hline \multicolumn{6}{|c|}{ SIR, SMR, and case-referent studies ${ }^{b}$} \\
\hline Blair et al,1990 (115) & United States & Dry cleaning (PS, PCE) & 1.2 & $0.7-1.9$ & 15.4 \\
\hline Lynge \& Thygesen, $1990(117)$ & Denmark & Laundry and dry cleaning (PS, PCE) & 1.7 & $1.1-2.6$ & 20.8 \\
\hline Ruder et al, 1994 (153) & United States & Dry cleaning ( $P C E)$ & 2.2 & $0.9-4.8$ & 5.5 \\
\hline Anttila et al, $1995(118)$ & Finland & Dry cleaning, etc (PCE) & 3.1 & $0.6-9.0$ & 2.1 \\
\hline Aggregate ${ }^{b}$ & & & 1.6 & $1.2-2.2$ & \\
\hline Aggregate (all studies) ${ }^{b}$ & & & 1.3 & $1.0-1.6$ & \\
\hline
\end{tabular}

a Numbers in parentheses recovered by us.

- In a matched case-referent study in Los Angeles, in the United States, Mack et al (16) did not calculate the odds ratio but instead reported the frequencies of laundrymen and cleaning service workers as pancreas cancer cases and referents. These numbers recover the crude $0 \mathrm{R}$, but the analysis becomes unconditional with regard to the matched design and may therefore be biased. The unconditional tabular reanalysis resulted in an odds ratio of $0.6(95 \%$ Cl $0.4-1.1)$, with a weight of 15.0 . When these figures were incorporated into the meta-analysis, the aggregated RR for SIR, SMR, and case-referent studies became $1.2(95 \% \mathrm{Cl} 1.0-1.6)$, and the overall aggregated RR was $1.1(95 \% \mathrm{Cl} 0.9-1.4)$. 
157). Risk ratios up to a level of 15 have been reported (156), and etiologic fractions have been estimated at $0.1-5 \%$ (5). Ekbom et al (158) demonstrated a marked excess risk of pancreatic cancer, particularly during the first year of follow-up after a diagnosis of chronic or acute pancreatitis. However, the risk approached unity at the 10th year of follow-up, suggesting a precursor role for pancreatitis. The inflammatory process inherent in pancreatitis may be a contributing factor to pancreatic cancer (159). A subgroup of idiopathic pancreatitis may be related to some types of occupational exposure (160162). The analysis of genetic alterations possibly involved in such a subgroup would enable an assessment of whether, in such cases, a link might exist between pancreatitis and exocrine pancreatic cancer.

\section{Diabetes mellitus}

Nine out of 11 case-referent studies and all 9 cohort studies demonstrated an association between pancreatic cancer and diabetes mellitus diagnosed at least 1 year before the diagnosis of pancreatic cancer (163). The association was significant in a meta-analysis and remained so when restricted to data on subjects who had had diabetes mellitus at least 5 years prior to the diagnosis of pancreatic cancer. Given the fast progression of pancreatic cancer, it is unlikely that the diabetes mellitus was explained by a local tumor infiltration in the pancreas. Moreover, in the 2 studies that distinguished between insulin-dependent diabetes mellitus and noninsulin-dependent diabetes mellitus, all pancreatic cancer patients had the latter (163).

\section{Genetic host factors}

Several cancer susceptibility syndromes have been found to be associated with pancreatic cancer, even though no definite conclusions can be drawn. The most important are hereditary nonpolyposis colon cancer in association with microsatellite instability, familial breast cancer in association with BRCA2 gene alterations, familial melanoma, atypical mole associated $\mathrm{p} 16^{\mathrm{INK} 4 \mathrm{~A}}$ gene alterations, ataxia telangiectasia, and von Hippel-Lindau disease $(151,164-167)$.

While 2 recent studies report familial clustering of pancreatic cancer, data on familial history are inconsistent. A case-referent study (84) in the Francophone community in Montreal, Canada, reported that $7.8 \%$ of pancreatic cancer patients had a family history of pancreatic cancer, compared with $0.6 \%$ of its matched referents. Another positive suggestion comes from Italy (168). A family cluster with pancreatic cancer through 3 generations has been reported (169). The genetic component in the familial aggregation of pancreatic cancer has been estimated at $2 \%$ in northern Italy (5).
Nonmalignant pancreatic pathologies, such as cystic fibrosis (170) and hereditary chronic pancreatitis (151, 171), appear to be associated with pancreatic cancer.

The role of genetic polymorphisms of metabolic enzymes in the modification of pancreatic cancer risk is unclear (50). It has been suggested that nitrosamines and aromatic amines might be the most probable pancreatic carcinogens. Several hypotheses explaining how carcinogens reach the pancreas have been postulated (151). While the levels of several P450 enzymes have been shown to be comparable or higher in pancreatic tissue than in liver tissue from organ donors and patients with chronic pancreatitis and pancreatic cancer $(160,172)$, it is not clear whether carcinogens are activated in the pancreas or whether the activation rather takes place in the liver before reaching the pancreas (151). The presence of heterocyclic amine adducts in pancreatic DNA (deoxyribonucleic acid), described in animal model studies, supports the idea that activated carcinogens are present in the pancreas. With regard to phase II enzymes, immunohistochemical analysis has shown no expression of glutathione S-transferase (GST) mu in normal or malignant pancreas, although GST pi was expressed only in pancreatic carcinoma tissue (173). No data are currently available on the role of $\mathrm{N}$-acetyl transferase enzyme in pancreatic carcinogenesis.

\section{Acquired genetic alterations}

Oncogenes such as Ki-ras, $m y c$, and $e r b B$-2; tumor suppressor genes (p53, p16 $6^{\mathrm{INK} 4 \mathrm{~A}}$, SMAD4/DPC-4, APC, $\mathrm{DCC}, \mathrm{Rb}$ ); and other acquired genetic alterations (RER phenotype, genetic amplification) have been proposed to be involved in pancreatic carcinogenesis.

The frequency $(75-95 \%)$ of mutations in codon 12 of the Ki-ras gene in pancreatic cancer is probably the highest among human neoplasms. The most frequent mutations are $\mathrm{G}$ to A transition (Asp substitution) and $\mathrm{G}$ to $\mathrm{T}$ transversion (Val substitution) in codon 12 (174-183). Pancreatic acinar and islet cell tumors probably do not harbor Ki-ras mutations $(50,184)$. Since Ki-ras mutations have also been found in ductal proliferative lesions of patients with and without pancreatic cancer (185188), and in cystadenomas (181), it has been postulated that this alteration would be an early event in pancreatic carcinogenesis, possibly associated with environmental carcinogens. Three retrospective studies have addressed smoking and Ki-ras mutations in pancreatic cancer. Two reported a weak or null association $(50,176)$, while one found a positive association but no dose-response (179). There are no data on the association between tobacco and mutational spectra. One study addressed alcohol drinking and $\mathrm{Ki}$-ras mutations in pancreatic cancer and 
reported a positive association (50), but the alcohol data were obtained from clinical records. Prospective data would be helpful to assess whether tobacco, alcohol, coffee, or other life-style or occupational and environmental factors contribute to the induction of pancreatic cancer through the activation of Ki-ras.

Mutations and loss of heterozygosity in the tumor suppressor gene p53 is present in up to $80 \%$ of pancreatic cancers (189). An analysis of the mutation spectrum in 159 pancreatic cancer cases included in the IARC p53 mutation database (190) showed that $27 \%$ of the tumors presented $\mathrm{C}: \mathrm{G}$ to $\mathrm{T}: \mathrm{A}$ transversions at $\mathrm{CpG}$ sites, suggesting an endogenous mutational process (191). This analysis also showed that the prevalence of $\mathrm{G}: \mathrm{C}$ to $\mathrm{T}: \mathrm{A}$ transversions and $\mathrm{G}: \mathrm{C}$ to $\mathrm{A}: \mathrm{T}$ transitions in pancreatic cancer is intermediate between colon and lung cancer, implying that some environmental factors may also play a role in the genesis of $p 53$ mutations in pancreatic cancer. However, no study has analyzed the association between environmental factors and p53 mutational spectra in pancreatic cancer. The $5 \mathrm{p} 53$ mutational hot spots identified from the data base were codons 175 and $249(3 \%)$, $248(4 \%), 273(13 \%)$, and $282(6 \%)$. The proportion of mutated pancreatic cancers in each of these codons also differs from those in lung and colon cancer. In addition, the finding of a higher frequency of microdeletions in purine and pyrimidine homocopolymer tracts described for the p 53 gene in pancreatic cancer, compared with other neoplasms (192), may contribute to information on additional environmental factors that are involved in pancreatic cancer.

p16 $6^{\mathrm{NK} 4 \mathrm{~A}}$ and SMAD4/DPC-4 have been reported to be lost or mutated in about $80 \%$ and $50 \%$ of pancreatic cancers, respectively $(193,194)$. A high concordance for the inactivation of both genes has been described (189). There are no available data on the association between environmental factors and $\mathrm{p} 16^{\mathrm{INK} 4 \mathrm{~A}}$ or SMAD4/DPC-4 alterations.

Under the hypothesis that the coexistence of mutations of several genes in a single tumor implies their involvement in distinct tumor pathways, Rozenblum et al (189) recently analyzed the alteration pattern of $\mathrm{Ki}$-ras, p53, p16 ${ }^{\mathrm{INK} 4 \mathrm{~A}}$, and SMAD4/DPC-4 genes in 42 pancreatic adenocarcinomas. Alterations in 3 or 4 of these genes were present in $76 \%$ of the tumors.

\section{Discussion}

In addition to refining exposure assessment, end-point delineation requires serious attention in pancreatic cancer epidemiology. Interpretations of differences in pancreatic cancer risk between populations and time periods may be obscured by variations in diagnostic practices. Up to $28 \%$ of histologically confirmed pancreatic cancers may in fact not have originated in the pancreas (195). Such misclassification rates induce biases in risk estimates for etiologic factors (196). For example, in a study on risk for pancreatic cancer and exposure to DDT and related compounds among chemical manufacturing workers, risk estimates were close to the null value among cases solely diagnosed from death certificates, while risk ratios increased to 15,21 , and infinite, depending on the chemical group, among cases with cytohistological confirmation (144). Similarly, in a study addressing the risk of pancreatic cancer associated with cigarette smoking, a substantial modification of risk by diagnostic certainty was observed (197). Improved general diagnostic accuracy and homogeneous histologic and molecular-level subgroups of pancreatic cancer are expected to allow for improvement in the assessment of etiologic factors (198).

No major risk factor except tobacco smoking has been established for pancreatic cancer. Either some environmental factors play a small etiologic role or the involvement of yet unknown endogenous factors is high, or both. In addition, interactions between environmental and endogenous factors may be important in the etiology of pancreatic cancer.

Early theories on biological mechanisms relating diet to pancreatic cancer postulated that some foodstuffs contain genotoxic compounds that cause gene mutations after absorption and, possibly, further metabolism. For example, the positive associations between pancreatic cancer and cured and grilled meats might be due to their nitrosamine and aromatic amine contents $(199,200)$. It has been also proposed that the effects of food consumption patterns on pancreatic cancer risk may be mediated by gastrointestinal hormones. Choleocystokinine-pancreazymin (CCK) (201-203) and secretin (204) have been postulated to promote cellular proliferation and growth in the pancreas, and it is a commonly held view that increased proliferation may sensitize the pancreas to an accumulation of genetic modifications caused by other agents, of either exogenous or endogenous origin. Among the strongest stimulators of CCK release are digestion products of protein and fats (205). Epidemiologic evidence does not, however, support the hypothesis that high intake levels of proteins, through the release of CCK, is a major risk factor of pancreatic cancer.

An alternative hypothesis is that pancreatic cancer may result from high exposures to insulin. There is ample evidence that noninsulin-dependent diabetes mellitus develops generally after prolonged periods, during which there is a gradual increase in insulin resistance of the liver and peripheral tissues $(206,207)$. Since pancreatic cancer has been related to this condition (163), it seems reasonable to assume that an increase in plasma insulin levels is a cause of pancreatic cancer. As the 
exocrine pancreas receives a large portion of its blood supply directly through the Langerhans islets where insulin is secreted into the blood (208), the pancreatic exposure to insulin is high when compared with that of tissues elsewhere, and it is possible that high postprandrial peak exposures to insulin promote the growth of pancreas tumors. Exposure to insulin has been reported to promote growth in 1 human pancreatic cell line out of the 2 that have been tested (209). Inversely, streptozotocin-induced diabetes mellitus causing an acute insulin deficiency was shown to prevent the development of pancreatic tumors in several animal models (210). Finally, there is evidence that an increased biological activity of insulinlike growth factor-I, together with other autocrine or paracrine factors, may be involved in the increased proliferation of pancreatic cells $(211,212)$, and it is well documented that insulin may increase the biological activity of IGF-I through the down-regulation of one of its binding proteins (IGFBP1) $(213,214)$.

The development of insulin resistance in noninsulindependent diabetes mellitus relates to obesity, in particular to the accumulation of high intraabdominal body fat stores $(206,207)$. The development of insulin resistance is strongly related to dietary factors and physical activity (215). In cross-sectional studies the dietary factor most clearly associated with the development of obesity, as well as with insulin resistance, is the intake of fat, especially saturated fats. High intakes of vegetables and fruit, on the other hand, have been found to be associated with less obesity and with less insulin resistance. Experimental studies have shown that water-soluble dietary fibers from fruit and vegetables may attenuate acute insulinemic responses to the consumption of foods rich in carbohydrates. For high intakes of refined carbohydrates and sugars, on the other hand, the relation with the development of obesity and insulin resistance is less clear. Regular physical activity is a well-defined protective factor against the development of insulin resistance. Given these various relations between nutritional life-style factors and plasma insulin concentrations, the hypothesis that a high endogenous exposure to insulin may be a cause of pancreatic cancer may fit well with the observation of higher pancreatic cancer incidence rates in industrialized Western societies. How other postulated risk factors fit with these hypotheses remains to be seen.

\section{Acknowledgments}

This work was partly supported by the European Community (DG-XII BIOMED-2 contract BMH4-CT951100) and the Finnish Work Environment Fund (grant 96248). Núria Malats was supported by special training awards from the International Agency for Research on
Cancer, Lyon, France, Direcció General de Recerca, Generalitat de Catalunya (CIRIT 1996BEAI300015), Spain, and the Fondo de Investigación Sanitaria (FIS 97/1138), Spain. We are grateful to Francisco X Real for critically reading the manuscript and to Paola Pisani for upgrading some of the descriptive data.

\section{References}

1. Pisani et al. Cancer Epidemiol Biomarkers Prev 1997;6:387400.

2. Brennan et al. In: DeVita et al, editors. Cancer: principles and practice of oncology. Philadelphia (PA): JB Lippincott Co, 1993:849-82.

3. Parkin et al. Cancer incidence in five continents; vol VII. Lyon: International Agency for Research on Cancer, 1997.

4. Parkin et al. Int J Cancer 1993;54:594-606.

5. Fernandez et al. Cancer Epidemiol Biomarkers Prev 1996;5:23-7.

6. Coleman et al. Trends in cancer incidence and mortality. Lyon: International Agency for Research on Cancer, 1993.

7. Estève et al. Facts and figures of cancer in the European Community. Lyon: International Agency for Research on Cancer, 1993.

8. Zheng et al. Int J Cancer 1995;61:622-7.

9. Pisani. In: Pearce et al, editors. Occupational cancer in developing countries. Lyon: International Agency for Research on Cancer, 1994.

10. Geddes et al. Cancer in Italian migrant populations. Lyon: International Agency for Research on Cancer, 1993.

11. Geddes et al. Tumori 1994;80:19—23.

12. Kogevinas et al. Social inequalitites and cancer. Lyon: International Agency for Research on Cancer, 1997.

13. International Agency for Research on Cancer. Tobacco smoking, Lyon: IARC, 1986.

14. Moolgavkar \& Stevens. JNCI 1981;67:15-23.

15. Gold et al. Cancer 1985;55:460—7.

16. Mack et al. JNCI 1986;76:49-60.

17. Silverman et al. JNCI 1994;86:1510 -6.

18. Shibata et al. Int J Cancer 1994;58:46 -9.

19. La Vecchia et al. Int J Cancer 1987;40:309-13.

20. Ishii et al. Digestion 1973;9:429-37.

21. Williams et al. JNCI 1977;58:525-47.

22. Jick \& Dinan. Lancet 1981;2:92.

23. Severson et al. Br Med J 1982;285:214.

24. Carstensen et al. J Epidemiol Community Health 1987;141:166-72.

25. Cuzick \& Babiker. Int J Cancer 1989;43:415-21.

26. Ferrarroni et al. Int J Epidemiol 1989;18:556-62.

27. Olsen et al. Am J Public Health 1989;79:1016-9.

28. Farrow \& Davis. Int J Cancer 1990;45:816-20.

29. Tomioka et al. Cancer Lett 1990;55:121-8.

30. Baghurst et al. Am J Epidemiol 1991;134:167—79.

31. Howe et al. Int J Cancer 1991;47:232- -8.

32. Ghadirian et al. Cancer 1991;67:2664-70.

33. Bueno De Mesquita et al. Int J Cancer 1991;49:816-22.

34. Lyon et al. Epidemiology 1992;3:164-70.

35. Friedman et al. Int J Epidemiol 1993;22:30 - 7.

36. Kalapothaki et al. Cancer Causes Control 1993;4:375-82.

37. Zatonski et al. Int J Cancer 1993;20:601-7. 
38. Ji et al. Cancer Causes Control 1995;6:369-76.

39. Hiatt et al. Int J Cancer 1988;41:794-7.

40. Hsieh et al. New Engl J Med 1986;315:587-95.

41. Norell et al. Am J Epidemiol 1986;124:894-902.

42. Mills et al. Cancer 1988;61:2578-85.

43. Wynder et al. Cancer Res 1986;46:5360-3.

44. Zheng et al. Cancer Causes Control 1993;4:477-82.

45. Boyle et al. Int J Cancer 1996;67:63-71.

46. Clavel et al. Int J Cancer 1989;43:17-21.

47. Durbec et al. Br J Cancer 1983;47: 463-70.

48. Falk et al. Am J Epidemiol 1988;128:324-36.

49. Hecht et al. Cancer Res 1994;57:1912s-17s.

50. Malats et al. Int J Cancer 1997;70:661-7.

51. International Agency for Research on Cancer (IARC). Alcohol drinking. Lyon: IARC, 1988.

52. Dörken. Gastroenterologia 1964;102:65-77.

53. Ansari et al. Am J Gastroenterol 1968;50:456-75.

54. Burch \& Ansari. Arch Int Med 1968;122:273-5.

55. Heuch et al. Br J Cancer 1983;48:637-43.

56. Hirayama. Jpn J Clin Oncol 1989;19:208-15

57. Velema et al. Epidemiol Rev 1986;8:28-41.

58. Silverman et al. Cancer Res 1995;55:4899-905.

59. Wynder et al. JNCI 1973;50:645-57.

60. MacMahon et al. New Engl J Med 1981;304:630-3.

61. Manousos et al. Cancer Det Prev 1981;4:439-42.

62. Gorham et al. West J Med 1988;148:48-53.

63. Bouchardy et al. Int J Cancer 1990;45:842-6.

64. Bueno de Mesquita et al. Int J Cancer 1992;50:514-22.

65. Mizuno et al. Jpn J Clin Oncol 1992;22:286-91.

66. Raymond et al. Gastroenterolog Clin Biol 1987;11:488—92.

67. Sen et al. In: Walker et al, editors. N-Nitroso coumpounds analysis, formation and occurrence. Lyon: International Agency for Research on Cancer (IARC), 1980:457-65.

68. Gullo et al. Pancreas 1995;11:223-9.

69. Elinder et al. Läkartidningen 1981;78:3676-7.

70. Goldstein. N Engl J Med 1982;310:783-5.

71. Whittemore et al. J Chronic Dis 1983;36:251-6.

72. Kinlen \& McPherson. Br J Cancer 1984;49:93-9.

73. Kinlen et al. Lancet 1984;1:282-3.

74. Snowdon \& Phillips. Am J Public Health 1984;74:820-3.

75. Jacobsen et al. JNCI 1986;76:823-31.

76. Jain et al. Int J Cancer 1991;47:384—9.

77. Partanen et al. Prev Med 1995;24:213-6.

78. Stensvold \& Jakobsen. Cancer Causes Control 1994;5:4018.

79. Vineis. JNCI 1993;85:1004-5.

80. Lea. Ann Roy Coll Surg 1967;41:432-8.

81. Armstrong \& Doll. Int J Cancer 1975;15:617-31.

82. Maruchi et al. Jpn J Cancer Res 1977;68:1-13.

83. Yanai et al. Environ Health Perspect 1979;32:83-101.

84. Ghadirian et al. Int J Cancer 1991;47:1-6.

85. Goto et al. Jpn J Cancer Clinics 1990;36:344-50.

86. La Vecchia et al. Oncology 1990;47:463-6.

87. Negri et al. Int J Cancer 1991;48:350 - 4.

88. Bueno de Mesquita et al. Int J Cancer 1991;48:540-9.

89. Lyon et al. Cancer Epidemiol Biomarkers Prev 1993;2:51318.

90. Farrow \& Davis. Am J Epidemiol 1991;132:423-31.

91. Howe et al. Int J Cancer 1990;47:463-6.

92. Zatonski et al. Int J Cancer 1991;48:390-4.

93. Howe et al. Int J Cancer 1992;51:365-72.

94. Howe \& Burch. Cancer Causes Control 1996;7:69-82.

95. Kalapothaki et al. Cancer Causes Control 1993;4:383-9.

96. Comstock et al. Am J Clin Nutr 1991;53:260s-264s.
97. Moller et al. Eur J Cancer 1994;30A:344-50.

98. Bueno de Mesquita et al. Int J Cancer 1990;45:435- 44.

99. Ijsselmuiden et al. Am J Epidemiol 1992;136:836-42.

100. International Agency for Research on Cancer (IARC). Chlorinated drinking-water; chlorination by-products some other balogenated compounds; cobalt and cobalt compounds. Lyon: IARC, 1991.

101. Black et al. Br J Cancer 1994;69:140-3.

102. Trédaniel et al. Eur J Cancer 1993;29A:2058-68.

103. Siemiatycki et al. In: J. Siemiatycki, editor. Risk factors for cancer in the workplace. Boca Raton (FL): CRC Press, 1991:141-295.

104. Falk et al. Am J Ind Med 1990;18:565-76.

105. Mur et al. Int J Epidemiol 1987;16:257—64.

106. Carta et al. Med Lav 1992;83:530-35.

107. Rockette et al. J Occup Med 1983;25:549-57.

108. Hansen. Scand J Work Environ Health 1989;15:43-6.

109. Mancuso \& El-Attar. J Occup Med 1966;9:277-85.

110. Bond et al. Am J Ind Med 1985;7:109-21.

111. Hanis et al. J Occup Med 1982;24:203-12.

112. Katz \& Jowett. Am J Public Health 1981;71:305-7.

113. Duh \& Asal. Am J Public Health 1984;74:1278-80.

114. Petrone. Cancer mortality among petroleum solvent exposed Oklahoma dry cleaners. Dissert Abst Int 1988;48:1955-B.

115. Blair et al. Br J Ind Med 1990;47:162-8.

116. Nakamura. Sangyo-Igaku 1985;27:24-37.

117. Lynge \& Thygelsen. Scand J Work Environ Health $1990 ; 16: 108-12$.

118. Antilla et al. J Occup Environ Med 1995;37:797-806.

119. Vena et al. Br J Ind Med 1985;42:85-93.

120. Mallin et al. Am J Ind Med 1986;10:127-41.

121. Silverstein et al. J Occup Med 1988;30:706-14.

122. Carstensen et al. Int J Cancer 1990;45:393-6.

123. Magnani et al, Br J Ind Med 1987;44:769-76.

124. Constantini et al. Br J Ind Med 1989;46:384—8.

125. Edling et al. Br J Ind Med 1986;43:494-6.

126. Decoufle et al. A retrospective survey of cancer in relation to occupation. Cincinnati (OH): DHEW-NIOSH, 1987. Publication no 77-1978.

127. Pickle \& Gottlieb. Am J Public Health 1980;70:256-9.

128. Thomas et al. J Occup Med 1980;22:97-103.

129. Lloyd et al. J Occup Med 1977;19:543--50.

130. Mallin et al. Am J Ind Med 1989;15:699-717.

131. Zoloth et al. JNCI 1986;76:1047-51.

132. Wingren et al. Am J Ind Med 1991;20:769-74.

133. Bross et al. Arch Environ Health 1978;33:300-7.

134. Henneberger et al. Br J Ind Med 1989;46:658—64.

135. Monson \& Fine. JNCI 1978;61:1047-_53.

136. Delzell et al. Am J Ind Med 1981;2:209-16.

137. Solenova. Vopr Onkol 1992;38:1174-82.

138. Olsen \& Jensen. Scand J Work Environ Health 1987;13 suppl $1: 1-91$.

139. Partanen et al. Am J Ind Med 1994;25:851-66.

140. Kawachi et al. Cancer 1989;64:2609-13.

141. Kauppinen et al. Epidemiology 1995;6:498-502.

142. Eisen et al. Am J Ind Med 1992;22:809 - 24.

143. Garabrant et al. JNCI 1992;84:764-71.

144. Garabrant et al. JNCI 1993;85:328-9.

145. Kogevinas et al. Scand J Work Environ Health 1994;20:25161.

146. Selenskas et al. Am J Ind Med 1995;28:385-98.

147. Anttila et al. J Occup Environ Med 1995;37:797-806.

148. Kolstad et al. Occup Environ Med 1995;52:320-7.

149. Anttila et al. Worker exposure to solvents and cancer: final 
report. Helsinki: Finnish Institute of Occupational Health, 1996.

150. Pannett et al. Br J Ind Med 1985;42:777—83.

151. Anderson et al. In: Schottenfeld et al, editors. Cancer epidemiology and prevention. New York (NY): Oxford University Press, 1996:725-71.

152. International Agency for Research on Cancer (IARC). Dry cleaning, some chlorinated solvents and other industrial chemicals. Lyon: IARC, 1995.

153. Ruder et al. J Occup Med 1994;36:867—74.

154. Lin \& Kessler. J Am Med Assoc 1981:245:147-52.

155. Lowenfels. Gastroenterol 1984;87:744.

156. Lowenfels et al. N Engl J Med 1983;328:1433-7.

157. Fernandez et al. Pancreas 1995;11:185-9.

158. Ekbom et al. JNCI 1994;86:625-7.

159. Andrén-Sandberg et al. Scand J Gastroenerol 1997;32:97103.

160. Foster et al. J Pathol 1993;169:457—63.

161. Braganza et al. Int J Pancreatol 1986;1:9-19.

162. McNamee et al. Occup Environ Med 1994;51:631-7.

163. Everhart \& Wright. JAMA 1995;273:1605-69.

164. Lynch \& Fusaro. Pancreas 1991;6:127-31.

165. Swift et al. N Engl J Med 1991;325:1831 -6.

166. Goldstein et al. N Engl J Med 1995;333:970-4.

167. Ozcelik et al. Nat Genet 1997;16:17-8.

168. La Vecchia et al. Cancer 1992;70:50-5.

169. Lynch et al. Pancreas 1992;7:511-5.

170. Neglia et al. N Engl J Med 1995;332:494-9.

171. Lowenfels et al. JNCI 1997;89:442-6.

172. Chassagne et al. Gastroenterology 1995;108:A348.

173. Collier et al. Gut 1994;35:266-9.

174. Almoguera et al. Cell 1988:53:549-54.

175. Grunewald et al. Int J Cancer 1989;43:1037-41.

176. Nagata et al. Jpn J Cancer Res 1990; 81:135-40.

177. Tada et al. Cancer 1991;67:634-7.

178. Tada et al. Gastroenterology 1991;100:233-8.

179. Hruban et al. Am J Pathol 1993;143:545-54.

180. Motojima et al. Ann Surg 1993; 217:138-43.

181. Berrozpe et al. Int J Cancer 1994;58:185—91.
182. Scarpa et al. Int J Cancer 1994;57:167-71.

183. Finkelstein et al. Arch Surg 1994;129:367-72.

184. Hoorens et al. Am J Pathol 1993;143:685-98.

185. Yanagisawa et al. Jpn J Cancer Res 1993;84:474—9.

186. Yanagisawa et al. Cancer Res 1993;53:953-6.

187. Tabata et al. Int J Pancreatol 1993;14:237- 44.

188. Tada et al. Gastroenterology 1996;110:227 - 31 .

189. Rozenblum et al. Cancer Res 1997;57:1731-34.

190. Hainaut et al. Nucleic Acids Res 1997;25:151-7.

191. Denissenko et al. Proc Natl Acad Sci USA 1997;94:3893-8.

192. Redston et al. Cancer Res 1994:54:3025-33.

193. Caldas et al. Nat Genet 1994;8:27-32.

194. Hahn et al. Science 1996;271:343-50.

195. Lyon et al. Int J Epidemiol 1989;18:305-8.

196. Porta et al. J Clin Epidemiol 1994;47:1069-79.

197. Silverman et al. J Clin Epidemiol 1996;49:601-2.

198. Jones et al. Cancer Res 1991;51:3617-20.

199. Sugimura \& Sato. Cancer Res 1993:43:2415s - 21s.

200. Ito et al. Carcinogenesis 1991;12:1503-6.

201. Levison. J Pathol 1979;129:203-3.

202. Howatson \& Carter. Br J Cancer 1985;51:107-14.

203. Smith et al. Dig Dis Sci 1990;35:1377-84.

204. Howatson \& Carter. JNCI 1989;78:101-5.

205. Walsh. In: Johnson et al, editors. Physiology of the gastrointestinal tract; vol 1. New York (NY): Raven Press, 1987:181254.

206. Reaven. Diabetes 1988;37:1595—607.

207. Defronzo. Diabetes 1988;37:667—87.

208. Williams \& Coldfine. Diabetes 1989;34:980-6.

209. Takeda \& Escribano. J Cancer Res Clin Oncol 1991;117:416-20.

210. Fisher et al. J Surg Res 1995;58:754-8.

211. Ohmura et al. Cancer Res 1990;50:103-7.

212. Perilli et al. Int J Pancreatol 1993;13:159—68.

213. Brismar et al. J Endocrinol Invest 1988;11:599—602.

214. Suikkari et al. J Clin Endocrinol Metab 1988;66: 266-72.

215. Kaaks. Cancer Causes Control 1996;7:605-25.

Received for publication: 11 February 1998 